\title{
Humanização em contexto pediátrico: \\ o papel dos palhaços na melhoria do ambiente vivido pela criança hospitalizada
}

\author{
Carla Hiolanda Esteves (a) \\ Conceição Antunes ${ }^{(b)}$ \\ Susana Caires ${ }^{(\mathrm{c})}$
}

Esteves $\mathrm{CH}$, Antunes $\mathrm{C}$, Caires $\mathrm{S}$. Humanization in a pediatric context: the role of clowns in improving the environment experienced by hospitalized children. Interface (Botucatu). 2014; 18(51):697-708.

In order to place value on the importance of psychosocial aspects of pediatric hospitalization, and to seek the child "behind" the sick body, many hospitals have been investing in humanizing their spaces, routines, and atmospheres aiming welcoming environments that will reduce the negative experiences of the children and their families during the hospital stay. In this paper, an attempt was made to systematize some of the efforts undertaken so far to define the concept of "humanization" specifically in the pediatric context. Reflections on the potential of some existing programs within this context are also provided, specifically those that combine art, recreation, leisure activities and humor as preferred means of communication and expression. Among these, interventions by hospital clowns are highlighted as promoters of free expression among children, along with autonomy, creativity, exploration, and knowledge of the world, with consequent psychosocial development.

Keywords: Pediatrics. Humanization. Hospital clowns.
Valorizando a importância dos aspetos psicossociais da internação pediátrica, e procurando a criança "por detrás" do corpo doente, vários hospitais têm investido na humanização de espaços, rotinas e atmosfera, procurando promover ambientes acolhedores e atenuantes das experiências negativas vividas pela criança (e família) durante a internação. A par de uma tentativa de sistematização de alguns dos esforços realizados até a data em nível da definição do conceito de "humanização" - nomeadamente em contexto pediátrico -, reflete-se acerca das potencialidades de alguns programas existentes nesse contexto, nomeadamente aqueles que aliam a arte, a recreação, o lazer e o humor como meios privilegiados de comunicação e expressão. Entre estes, destaca-se a intervenção dos palhaços de hospital, como promotora da livre expressão da criança, da sua autonomia, criatividade, exploração e conhecimento do mundo e consequente desenvolvimento psicossocial.

Palavras-chave: Pediatria. Humanização. Palhaços de hospital. (a) Doutoranda em Psicologia da Educação, Instituto de Educação (Braga - Portugal), Universidade do Minho. Rua D. Afonso Henriques, $n^{\circ} 252$, Brito. 4805-052. Guimarães, Portugal. hiolandaesteves@ gmail.com $(b, c)$ Instituto de Educação, Universidade do Minho. Braga, Portugal. mantunes@ ie.uminho.pt; s.caires@sapo.pt 


\section{Introdução}

Na última década, em nível internacional e nacional, no caso vertente Portugal, vários têm sido os investimentos realizados no sentido de definir o conceito de "humanização" em contexto de saúde, e analisar as mais-valias dos projetos que visam a sua operacionalizaçãa ${ }^{1-4}$. Segundo Vaitsman e Andrade $^{5}$, o conceito de humanização em contexto de saúde surge ligado ao paradigma dos Direitos Humanos. Efetivamente, na Declaração Universal dos Direitos do Homem ${ }^{6}$, está implícita esta relação, dado que esta se funda na noção de dignidade e igualdade de todos os seres humanos.

De acordo com a revisão da literatura realizada, a humanização hospitalar evidencia-se como um bem e uma necessidade reconhecida, quer ao nível das conceções teóricas, quer entre os usuários dos serviços $^{7}$. Apesar de este conceito estar habitualmente associado à ideia de um atendimento afetuoso, empático e atento às necessidades do paciente, a humanização é um desafio transversal a todos os atores em saúde. Adicionalmente, a humanização vai para além de quem é cuidado, mas, envolvendo, também, os seus cuidadores e demais atores do contexto hospitalar. Inclusivamente, no Brasil, a humanização assumiu um caráter mais formal com a Política Nacional de Humanização ${ }^{8}$. Tal como refere Lepargneur (2003 citado por Mota, Martins e Véras"), humanizar consiste em "saber promover o bem comum acima da suscetibilidade individual ou das conveniências de um pequeno grupo" ( $p$. 234), assumindo-o como um processo partilhado por todos, e focado na promoção da colaboração interdisciplinar entre profissionais, entre estes e os usuários, e entre todos eles e os próprios cuidadores informais (família, acompanhantes...). Duarte e Noro ${ }^{10}$ assumem a humanização hospitalar como devendo consistir em " [...] ofertar atendimento de qualidade, articulando os avanços tecnológicos com o acolhimento, com melhorias dos ambientes de cuidado e das condições de trabalho dos profissionais" (p. 689). Para que tal possa acontecer, Machado, Haddad e Zoboli11 reivindicam a necessidade de se proceder à "...transformação cultural da gestão e das práticas desenvolvidas nas instituições de saúde, assumindo uma postura ética de respeito ao outro, de acolhimento do desconhecido, de respeito ao usuário entendido como um cidadão e não apenas como um consumidor de serviços de saúde" (p. 448).

Machado e colaboradores ${ }^{11}$, na sua revisão da literatura, realçam a dificuldade da sua implementação e, reportando-se à prática da enfermagem, referem que "[...] o aspeto humano do cuidado, com certeza, é um dos mais difíceis de ser implementado" (p. 686). Segundo Sá12, tal dificuldade prende-se com o facto de existir, ainda hoje, uma "inadequação para designar o que pretende" (p. 653), revestindo-se a sua definição, frequentemente, de marcada subjetividade, levando a múltiplas interpretações, e a modos de implementação diferenciados e, não raras vezes, ineficazes para atingir o seu real objetivo. Um outro obstáculo prende-se com o facto de, ainda hoje, prevalecer, na nossa sociedade, uma grande valorização do estatuto social e profissional da classe médica ${ }^{12}$. A formação superior do corpo médico faz, destes profissionais, uma classe considerada, por muitos, uma "elite", com a qual o contacto é baseado no respeito e obediência, mais do que num sentimento de empatia, ajuda e compreensão. A este entrave à humanização, acresce-se a falta de investimento na reflexão e estruturação de meios reais, promotores de uma efetiva cultura hospitalar humanizada, bem como ao nível da formação dos profissionais, recorrentemente salientados na literatura da área ${ }^{12-18}$.

A estes obstáculos, Costa (2000, citado por Sá ${ }^{12}$ ) e Morais et al. ${ }^{19}$ acrescentam a inadequação dos espaços e respetiva falta de dinamização, bem como as características dominantes da sociedade em que vivemos, onde o consumismo, o egocentrismo, a estratificação social, a desvalorização das classes menos alfabetizadas e/ou de outras etnias e nacionalidades dão corpo à cultura do "ter" e do "parecer" em detrimento do "ser". Adicionalmente, a "supervalorização da dimensão económica" e a "obsessão pela modernização, junto com uma idealização da técnica e da tecnologia" (p. 655) são também salientados por Enriquez (1994, citado por Sá12). 


\section{A humanização em contexto pediátrico}

Falar em humanização, nos cuidados pediátricos, adquire um significado mais relevante. Tal relevância deve-se, por um lado, à maior imaturidade da criança para compreender a sua situação clínica, o internamento hospitalar e todos os tratamentos a que é sujeita; e, por outro, à vulnerabilidade acrescida que o afastamento do seu meio familiar, o contacto com pessoas, ambientes e equipamentos estranhos ou, por exemplo, a privação do brincar poderão acarretar 15,20,21. Efetivamente, neste contexto específico onde a humanização, a personalização e os cuidados específicos se esperariam como valores "nucleares", estes são descurados. O trabalho de Gomes e Erdmann ${ }^{22}$, descrevendo a experiência hospitalar da criança como frequentemente fracionada, onde a criança é segmentada "[...] em órgãos ou em patologias, sendo até mesmo apontada, por alguns profissionais, pelo número de seu leito, totalmente desqualificada e expurgada de sua identidade e de sua cidadania" (p. 25), ilustra algumas das práticas que ainda vigoram em contexto pediátrico. Neste tipo de práticas - não tão invulgares quanto o desejável -, Troostwijk ${ }^{23}$ (p. 73) refere que, muito facilmente, a criança se torna "num caso de...". Por exemplo, no Brasil, muito embora a presença do acompanhante para a criança seja garantida por Lei, pelo Estatuto da Criança e Adolescente - Capítulo I, arto $12^{24}$, tal nem sempre acontece.

Procurando sistematizar os eixos em que deverá assentar a humanização hospitalar, nomeadamente no contexto pediátrico, a literatura tem vindo a centrar-se, essencialmente, na reflexão e sugestão de medidas em nível: (i) da melhoria dos cuidados ao paciente pediátrico; (ii) da melhoria dos processos de comunicação interpessoal entre os diferentes agentes hospitalares; (iii) da melhoria das condições de trabalho dos profissionais de saúde, e (iv) da melhoria da qualidade da "atmosfera" hospitalar.

Dado o particular interesse dos autores por este último tópico, não só pelo maior protagonismo que tem vindo a receber mais recentemente, em Portugal, mas pela área de investimento que tem marcado o seu trabalho mais recente - a intervenção de palhaços profissionais em pediatria -, dar-se-lhe-á especial relevo ao longo deste trabalho.

\section{Medidas para a melhoria da qualidade do ambiente pediátrico}

Representando, o internamento, uma transição ecológica ${ }^{25}$ que altera a relação da criança com os seus ambientes próximos, vários são os estudos que têm vindo a procurar identificar os principais fatores de estresse associados à vivência, pela criança, das rotinas, serviços, espaços e agentes que integram o cenário pediátrico, bem como a intensidade com que são experienciados. Adicionalmente, o impacto destes fatores no bem-estar físico e psicológico da criança, na qualidade do seu internamento e no processo de recuperação, ou, ainda, os efeitos ao nível do seu desenvolvimento, a médio e longo prazo, têm também vindo a ser alvo de análise ${ }^{1,25-29}$. Mazur et al. ${ }^{27}$ (p. 5), procurando retratar a experiência de hospitalização infantil, referem que "Quando uma criança é internada, o ambiente estranho a assusta, pois há pessoas que não Ihe são familiares, ruídos diferentes e uma dinâmica de funcionamento desconhecida". Masetti ${ }^{29}$ destaca, neste ambiente estranho, o efeito dos "aparelhos computadorizados, as luzes que piscam... as transfusões de sangue que limitam seus movimentos, as pessoas que ali trabalham, com suas roupas brancas e comportamentos estereotipados... os tubos e as máscaras de oxigênio que dificultam se movimentar e ultrapassarem sua condição de paciente" ( $p$. 2). Segundo a autora, a privação das crianças das suas roupas, dos seus brinquedos e do brincar fazem do hospital e da experiência de internamento "uma realidade que destitui a criança da sua função: ser criança" (p. 2), ficando a sua vida "suspensa" no momento em que entra no hospital.

A sensação de desamparo gerada pelo afastamento do seu ambiente familiar, pelo confronto com o desconhecido e o imprevisível, ou a não-compreensão de determinadas normas, rotinas e procedimentos, são apontados como responsáveis por alguns comportamentos regressivos (por exemplo: enurese, chuchar no dedo), fobias (por exemplo: a agulhas, jalecas brancas, procedimentos médicos), pesadelos e/ou alterações de comportamento que dificultam a sua socialização hospitalar (por exemplo: agressividade, mutismo, isolamento) ${ }^{25,28,30-34}$. São também comuns as reações de protesto e medo devido à falta de entendimento e compreensão sobre a sua situação, ou de apatia e 
fuga como formas de lidar com os elevados níveis de ansiedade resultantes da não-compreensão e falta de controle sobre diferentes aspetos da nova situação ${ }^{34,35}$.

Cada vez mais conscientes do impacto que o ambiente hospitalar pode ter no bem-estar, recuperação e desenvolvimento da criança, e procurando ampliar a importância dos aspetos psicossociais - indissociáveis dos aspetos físicos - do internamento, vários hospitais têm vindo a investir na humanização dos seus espaços, rotinas e ambientes, procurando torná-los mais acolhedores e atenuadores das experiências negativas vividas pela criança (e sua família) durante o internamento 1-3,36. Defensores destas ideias, Schmitz et al. ${ }^{34}$ e Oliveira et al. ${ }^{38}$ postulam que, durante a hospitalização, devem assegurar-se experiências que permitam que a criança se sinta amada, protegida, tenha confiança em si e nos adultos de quem depende; que o acompanhamento por parte dos seus cuidadores respeite, por um lado, as etapas evolutivas e marcos do seu desenvolvimento e, por outro, promova experiências potenciadoras desse desenvolvimento; a satisfação das suas necessidades (e curiosidades); bem como, a concretização das suas capacidades e "vocações". Tais experiências passam, atualmente, pelo desenvolvimento de iniciativas internas e pelo recurso à colaboração de elementos externos à instituição, tal como a literatura na área revela.

\section{Medidas internas}

Entre as medidas internas que o movimento de humanização pediátrica fomentou nos hospitais, destacam-se: a possibilidade de a criança ter um acompanhante; o encorajamento dos pais para assumirem um papel ativo no cuidado da criança; o receber visitas; a dinamização de espaços lúdicos (por exemplo, ludotecas/brinquedotecas); a instalação de redes informáticas; ou a adequação da decoração ao público pediátrico 1,26,27,36,37-39. Entre estas, destacamos a dinamização de espaços lúdicos e a adequação dos espaços ao paciente pediátrico, ambos alvo de particular relevo nas mais recentes intervenções em contexto hospitalar, em resposta aos objetivos de promoção de ambientes humanizados, e às necessidades psicossociais do paciente pediátrico.

\section{Dinamização de espaços lúdicos}

A criação de espaços lúdicos em contexto pediátrico tem vindo a ser apontada como essencial ao bem-estar, desenvolvimento e distração da criança hospitalizada. Nestes, a criança encontra: novas possibilidades para a ocupação do seu tempo livre; estímulos relevantes ao seu desenvolvimento (cognitivo, social, emocional, psicomotor...), à sua autonomia e, entre outros, uma oportunidade de abstração em relação aos múltiplos estressores associados à sua condição clínica e tratamento. A propósito deste último, Barros ${ }^{21}$ refere o facto de que, enquanto a criança brinca, esta está capaz de descentralizar o seu foco de preocupação (na doença e nos procedimentos invasivos), para outras situações/estímulos distratores.

Outros autores sinalizam o brincar como um meio privilegiado de exploração e expressão dos medos, anseios e receios da criança ${ }^{20,34,40}$, acentuando Tavares ${ }^{41}$ seu valor terapêutico. Segundo este último autor, quando a criança brinca, ela adquire os meios para libertar o estresse e a tensão gerados pelas suas vivências na interação com o ambiente. Este aspeto tem um importante valor na criança saudável, mas, mais ainda, na criança hospitalizada, constituindo-se numa importante estratégia para a auxiliar a libertar-se do estresse e medo inerentes à doença, hospitalização e tratamentos.

É também uma forma de compreender, por meio da simulação lúdica, os procedimentos e intervenções de que é alvo, podendo, igualmente, surgir como um "canal" de comunicação alternativo da criança com os seus cuidadores, e adicionando importantes ganhos na sua confiança relativamente aos profissionais de saúde ${ }^{20,42}$. Segundo Parcianello e Fellin ${ }^{1}$, brincar poderá, igualmente, contribuir para a desmistificação das representações da criança (e dos seus pais) em relação aos seus cuidadores formais, humanizando a relação entre ambos. Oliveira et al. ${ }^{43}$ apontam, também, para o seu papel complementar na recolha de informação sobre a criança. Favero et al. ${ }^{44}$ reforçam esta ideia afirmando que o modo como a criança brinca é indicador de como ela está e como ela é, sendo que, por meio da sua observação no ato de brincar, ou da participação direta nessas atividades lúdicas, é possível 
observar como raciocina, descobre, persiste ou reage, afetivamente, às múltiplas situações trazidas pelo jogo.

A estes autores associam-se vários outros que, a par dos ganhos já salientados, assumem o brincar no hospital como ajudando a criança a sentir-se mais segura num ambiente estranho, possibilitando uma mediação entre o mundo familiar e situações novas e ameaçadoras, e a elaboração de experiências desconhecidas e desagradáveis. Adicionalmente, poderá ajudar a minimizar a ansiedade da criança em momentos de separação dos pais/família e as saudades de casa e amigos. Pelo facto de colocar a criança numa posição ativa, oferece-lhe, também, a possibilidade de fazer escolhas e de se sentir "no comando", algo de que está privada em muitos dos momentos vividos no hospital15,34,41,45-47.

Mediante as inúmeras vantagens do brincar em contexto hospitalar, a criação de espaços lúdicos - ludotecas/ brinquedotecas - em contexto pediátrico tem sido uma realidade crescente em vários hospitais à escala nacional e internacional ${ }^{26,28,34,37}$.

\section{Adequação dos espaços às características e necessidades do paciente pediátrico}

Como referem Bergan et al., 7 "A compreensão do edifício hospitalar, assim como o planejamento e a qualidade de projetos de edifícios destinados ao atendimento à saúde com racionalização, adequação e humanização dos espaços, torna-se de fundamental importância" (p. 657). A este propósito, Goldenstein ${ }^{36}$ destaca aspetos, como a decoração, a luz, as cores dos espaços, como podendo ajudar a afastar "... o hospital humanizado da frieza do hospital tradicional" (p. 36). Segundo este autor, a criação de espaços amplos e luminosos, jardins, ou serviços de hotelaria e pequenas lojas, poderá concorrer para subtrair, ao hospital, a imagem de dor, sofrimento e morte.

A este propósito, Barros ${ }^{21}$ refere que a adequação dos espaços hospitalares ao público infantil implica, sobretudo, o aliar da criatividade a conhecimentos do desenvolvimento infantil. A existência de sinalização clara e acessível; a criação de áreas diferenciadas de jogo, descanso e tratamentos; a implementação de regras que permitam o controlo, pela família, das rotinas, atividades e a organização do seu próprio espaço, são exemplos de algumas destas medidas. Não implicando, necessariamente, custos elevados, estas medidas poderão assegurar uma significativa mudança da experiência de internamento pela criança e sua família. Para além da intervenção nos espaços físicos, outros autores apontam medidas como, por exemplo: a utilização de batas coloridas ou com motivos infantis; uma decoração infantil ou, ainda, o acesso, por parte da criança, a objetos adequados aos seus gostos, interesses e nível desenvolvimental ${ }^{1,20}$.

\section{Medidas implicando elementos externos ao hospital}

O crescente reconhecimento do impacto psicossocial do internamento hospitalar na criança e sua família, tem permitido, tal como visto até aqui, um gradual desviar do olhar da doença/situação clínica de que a criança é portadora para a pessoa "por detrás" do corpo doente e para as suas necessidades ${ }^{1,15,27}$. Adicionalmente, a própria concepção do hospital como um ambiente de dor e sofrimento passou, gradualmente, a dar lugar a um outro olhar, onde experiências que aliam a arte, a recreação, o lazer ou o humor passaram a assumir maior expressão entre as propostas de intervenção pediátrica $920,38,48$.

Dadas as especificidades destas intervenções, e a exigência de skills que vão para além do leque de competências dos profissionais que prestam cuidados à criança, grande parte destas experiências são promovidas por agentes externos ao hospital. Delas são exemplo: as sessões de magia ${ }^{49}$, o conto de histórias ${ }^{50}$, a música e os animais ${ }^{51}$, ou os palhaços de hospita|${ }^{48,52}$. O seu fim último prende-se com a oferta de um ambiente mais acolhedor para a criança (e sua família), no qual esta se sinta motivada e estimulada a participar, se relacionar, explorar e/ou brincar de forma mais ativa ${ }^{53}$. De entre estas, os palhaços de hospital têm vindo a conquistar um lugar privilegiado, sendo crescente o reconhecimento e atenção dada ao seu trabalho, tanto ao nível da sociedade em geral como no seio da própria comunidade científica que, na última década, foi sucessivamente relevando a mensuração e análise dos seus benefícios ao nível do bem-estar da criança e dos demais atores pediátricos. 


\section{A arte clown em contexto pediátrico}

$\mathrm{Na}$ ótica de $\mathrm{WuO}^{54}$, a arte clown no hospital é um canal privilegiado de "trânsito" de elementos essenciais a um processo contínuo de transformação, no qual a técnica artística - aliada à criatividade e à imaginação - surge como ferramenta-chave à introdução do lúdico e do humor nas diversas situações hospitalares.

A sua aparência assemelha-se, muitas vezes, à de um médico ou de um enfermeiro, usando batas, e a sua intervenção é organizada com recurso a instrumentos e procedimentos do dia a dia hospitalar, mescladas com truques, proezas e recreações "importadas" do mundo do circo e do teatro, podendo, por exemplo, um simples exame de otorrinolaringologia converter-se num jogo onde, inusitadamente, bolas de sabão "brotam" do ouvido da criança ${ }^{55}$.

Enquanto promotores e facilitadores do riso, os palhaços, de acordo com a autora, propagam um conforto que não se pode ver nem tocar, proporcionam um conforto interior, insubstituível, e até espiritual, ${ }^{55}$ e que concorrem para a "transformação" de que nos fala Wuo ${ }^{54}$. Tal como diz esta última autora, na interação com o palhaço "o paciente pode dançar, rir, correr, representar personagens e jogar [...] o corpo doente transforma-se [...] num corpo vivo, alegre, expressivo e criativo [...] procurando a sua recuperação" (p. 40).

Fazer com que a criança se sinta especial e única é uma das missões do palhaço. Esta é alcançada, quer por intermédio de visitas individualizadas ao quarto da criança, quer, entre outros, pela sua capacidade de aceitar os erros e transformá-los em recursos, enobrecendo a atitude do outro por mais absurda que ela seja ao olhar racional ${ }^{15}$, podendo esta abordagem ter repercussões na autoestima da criança e dos demais interlocutores do palhaço.

Tal como diz Melo ${ }^{46}$, no contexto pediátrico, a arte não é mero entretenimento, mas, sim, uma forma de linguagem que permite a comunicação com os outros, e que cria a possibilidade de organizar percepções, sentimentos e sensações. No caso da criança, a arte do palhaço permite-lhe expressarse livremente, e promover a sua autonomia, criatividade e exploração do mundo, possibilitando-Ihe, assim, ampliar o seu conhecimento sobre o mesmo e promover o seu desenvolvimento psicossocial. Trata-se de um excelente meio para canalizar, de maneira positiva, as variáveis do desenvolvimento da criança hospitalizada e neutralizar os fatores afetivos negativos associados à doença e à hospitalização ${ }^{56}$. Adicionalmente, segundo estes últimos autores, a arte do palhaço poderá também ter efeitos preventivos, evitando, por exemplo, o aparecimento e/ou instalação de algumas disfunções que possam comprometer o seu normal desenvolvimento.

A par dos ganhos já referidos, Masetti ${ }^{15}$ aponta a arte clown em contexto hospitalar como podendo concorrer para a criação de novas relações entre as situações, e o quebrar da lógica da previsibilidade, pelo facto de propor soluções incomuns no confronto com determinadas situações do cotidiano hospitalar. A presença e atuação do palhaço no hospital abrem a possibilidade de (não só à criança mas, também, aos adultos à sua volta) perceber os acontecimentos por meio de novas perspectivas, ampliando a percepção da realidade habitualmente construída. Ao ver a realidade hospitalar pelos olhos do palhaço, por exemplo, a criança passa a descobrir o divertimento nos aparelhos médicos e constrói um novo olhar sobre a doença, a hospitalização e muito do que envolve esta nova realidade ${ }^{57}$. Assim, o tubo do soro transforma-se numa grande palhinha e o soro é batido de chocolate; os eletrocardiogramas são televisões; a desinfeção das salas é feita com bolas de sabão; as cadeiras de rodas servem para fazer corridas; e os aparelhos de radioterapia são transformados em rádios com música para dançar. Com isto, pretende-se que os procedimentos médicos sejam desconstruídos e reconstruídos ao ritmo da imaginação de cada um.

Refira-se que Moreira $^{57}$ salienta que, apesar de a intervenção dos palhaços investir na desconstrução da realidade, esta não é encoberta ou escondida; pois as brincadeiras do palhaço estão, em muitas situações, de um outro prisma, ministrando, de forma lúdica, os tratamentos a que é habitualmente sujeita. Moreira ${ }^{57}$ salienta, também, que estas brincadeiras não diminuem, de forma direta, as dores e o sofrimento da criança, mas, sim, o medo perante os procedimentos responsáveis por eles. Segundo a autora, por intermédio destas brincadeiras, a criança tem a oportunidade de ver o tratamento e a doença de outra forma, ganhando predisposição para se sujeitar aos mesmos, 
tornando-os, geralmente, menos penosos, dolorosos e/ou traumáticos. Esta abordagem poderá ter particular utilidade, por exemplo, nas situações de preparação da criança para uma cirurgia, uma vez que permite a antecipação de alguns dos procedimentos de que será alvo, bem como da dor e limitações que poderão estar presentes no período pós-operatório ${ }^{52}$.

Acrescente-se que, embora o paciente pediátrico seja um dos principais focos da sua intervenção, o impacto dos palhaços expande-se a um público mais alargado, "contaminando" outros atores e dimensões do espaço pediátrico, tal como se foi deixando transparecer até aqui. Efetivamente, várias são as evidências que revelam iguais benefícios da presença dos palhaços no contexto pediátrico em dimensões como: a relação da criança com os médicos e restante equipe de cuidados; a relação da criança com os pais/acompanhantes e destes últimos com os profissionais de saúde; a relação existente no seio da equipe de profissionais; ou, por exemplo, a relação da criança e seus pais com a doença, tratamento e a experiência de internamento ${ }^{22,55,58}$.

\section{Reflexões finais}

Considerando algumas das reflexões que as leituras efetuadas nos suscitaram, parece-nos pertinente, em primeiro lugar, destacar, à semelhança de Oswald ${ }^{59}$, o contrassenso de falarmos da necessidade de humanização em contexto hospitalar. Efetivamente, esta problemática é, nos nossos dias, centro de muitas atenções, dado que, ao conceito de humanização, está ligado o conceito de qualidade, temática muito relevante no âmbito dos países desenvolvidos ou em vias de desenvolvimento, como é o caso específico de Portugal. A obtenção da certificação de qualidade tornou-se, atualmente, uma das maiores preocupações das organizações públicas ou privadas, sociais ou empresariais. É, no entanto, importante compreender que, tal como diz Brito, ${ }^{60}$ "Não é possível humanizar a gestão das organizações sem melhorar a qualidade, da mesma maneira que a procura da qualidade [...] traz consigo necessariamente a humanização das instituições" (p.33). A revisão de literatura efetuada conduziu-nos à ideia incontornável de que a humanização, em contexto hospitalar, independentemente do país e das políticas públicas de saúde existentes, é um conceito e uma prática que visam, fundamentalmente, melhorar a qualidade de vida dos usuários. Reiterando, humanização e qualidade de vida são dois conceitos indissociáveis que se interpenetram de tal forma que um se torna condição necessária à existência do outro.

Significativo é, também, compreender o facto de o conceito 'qualidade de vida' ser entendido na perspetiva da $\mathrm{OMS}^{61}$ como um conceito amplo, que abrange tanto a saúde física como psicológica da pessoa, o seu nível de independência assim como as suas relações sociais, suas crenças e convicções.

Nesta ótica, qualidade de vida e humanização não podem ser entendidas na mera perspetiva da preocupação pela melhoria da qualidade e eficácia dos serviços, mas, sim, na perspetiva holista e integral que caraterizam o ser humano, entendido como uma unidade complexa. Assim, o corpo doente não pode ser considerado apenas um dado biológico, mas, antes, um espaço psíquico, um substrato e via de expressão das emoções, do pensamento, da inteligência, da afetividade e da espiritualidade. Na esteira desta conceção holista, inter-relacional e dinâmica de entender o ser humano, humanizar e melhorar a qualidade de vida, em contexto hospitalar, particularmente em pediatria, corresponderá, certamente, a uma elevação da qualidade dos serviços a prestar, os quais não podem ser entendidos no sentido restrito dos procedimentos técnicos, e dos atos e resultados permitidos pelos cada vez "mais sofisticados aparelhos de diagnóstico e/ou as técnicas cirúrgicas mais precisas" (p.33) que Brito ${ }^{60}$ menciona. Assim, a qualidade dos serviços tem também de incluir os aspetos subjetivos, qualitativos e incomensuráveis caraterísticos "da relação interpessoal especialíssima" entre doente e médico e com os outros profissionais de saúde" ${ }^{59}$ (p. 27).

Decorrente deste raciocínio, realçamos a necessidade da promoção de relações pessoais positivas e significativas, para potenciar um sentimento de bem-estar - tanto da criança como do seu acompanhante -, bem como de confiança no hospital e, em particular, nos seus serviços e profissionais. Desta forma, as relações interpessoais - tanto entre a equipe de cuidados e o paciente, como entre os elementos desta equipe - devem ser repensadas. As primeiras devem assentar nos sentimentos 
de empatia e solidariedade com o sofrimento alheio, bem como no recurso a "linguagens", códigos e valores comuns, uma vez que os níveis tanto de formação pessoal como académicos podem ser diferentes. De entre estes valores, o respeito deverá nortear todo o processo, devendo a pessoa hospitalizada ser olhada para além de um corpo e de uma condição clínica que conduziu ao seu internamento. Como João dos Santos ${ }^{62}$ refere, o mais importante em medicina é a relação humana. De acordo com o mesmo autor, só uma relação e comunicação autênticas possibilitarão ao paciente comunicar o que pensa, sente e necessita, e, ao médico/seus cuidadores, compreender, devidamente, o que é reportado por este: "sem relação, não concebemos um diagnóstico humanamente válido [...] o importante é a relação, o contacto e a acção terapêutica deste contacto, para além da observação objectiva e da colheita das queixas, sinais e sintomas"62 (p. 71).

Pensamos ser precisamente nesta caraterística fundamental da relação e do seu potencial terapêutico - incontornáveis a um processo de humanização - que se inscreve a crescente relevância que a intervenção dos palhaços de hospital tem vindo a adquirir, tanto ao nível da comunidade civil e do senso comum, como da comunidade científica.

Estudos recentes acerca do papel da relação e das emoções na saúde corroboram as ideias anteriores ao evidenciarem que o

corte e a dor custam menos quando são acompanhados por uma expressão de bondade e de interesse. Ser notado, sentido e cuidado alivia a dor de uma forma muito significativa. A indiferença e a rejeição amplificam-na [...] um tom de voz que mostre interesse e envolvimento emocional faz com que as palavras do médico pareçam ajudar mais [...] quanto mais satisfeitos ficam os pacientes, melhor recordam as instruções do médico e mais fielmente as seguem. ${ }^{63}$ ( $p$. $368 ; 371)$

Em contexto pediátrico, esta faceta assume, ainda, maior relevância pela maior vulnerabilidade desenvolvimental da criança. Neste sentido, a intervenção dos palhaços do hospital não é puro entretenimento, mas, sim, uma forma de melhorar a comunicação, a relação e a aceitação da hospitalização e dos tratamentos, constituindo-se num fator importante de promoção de bem-estar e melhoria da qualidade de vida da criança hospitalizada.

Se a certificação e a qualidade são referenciais dos organismos da sociedade atual, a humanização dos serviços de saúde é uma meta incontornável, dado ter o seu ponto axial na qualidade e adequada relação intersubjetiva que, em termos éticos, é exigida "pelos mais fundamentais valores da pessoa humana, que por estar ou se apresentar doente, nada perde da sua dignidade, liberdade e autonomia" 59 (p. 27).

Se a humanização dos serviços de saúde é um ideal para o qual todos pretendem caminhar, a intervenção dos palhaços de hospital deve ser entendida como um significativo fator facilitador e promotor desse ideal. 


\section{Colaboradores}

Os autores participaram, igualmente, de todas as etapas de elaboração do artigo.

\section{Referências}

1. Parcianello AT, Felin RB. E agora doutor, onde vou brincar? Considerações sobre a hospitalização infantil. Barbarói Santa Cruz do Sul. 2008; 28:147-66.

2. Motta A, Enumo SRF. Brincar no hospital: estratégia de enfrentamento da hospitalização infantil. Psicol Estudo. 2004; 9(1):19-28.

3. Machado MM, Gioia-Martins D. A criança hospitalizada: espaço potencial e o palhaço. Bol Inic Cient Psicol. 2002; 3(1):34-52.

4. Valiate F, Tozzi V. A busca da humanização no ambiente hospitalar através dos Especialistas do Riso. Com Saúde [Internet]. 2001 [acesso 2010 Jan 6]. Disponível em: http://www.projetoradix.com.br/dsp_abstr.asp?fuseaction=10a\&id=173

5. Vaitsman J, Andrade GR. Satisfação e responsividade: formas de medir a qualidade e a humanização da assistência à saúde. Cienc Saude Colet. 2005; 10(3):599-618.

6. Organização das Nações Unidas. Declaração Universal dos Direitos Humanos. 1948 [acesso 2010 Jan 6]. Disponível em: https://dre.pt/comum/html/legis/dudh.html

7. Bergan C, Bursztyn I, Santos MCO, Tura LFR. Humanização: representações sociais do hospital pediátrico. Rev Gaucha Enferm. 2009; 30(4):656-61.

8. Angnes DI, Bellini MIB. Política de humanização da assistência à saúde/RS: trajetória e consolidação. Bol Saude 2006; 20(2):11-20.

9. Mota RA, Martins CGM, Véras RM. Papel dos profissionais de saúde na política de humanização hospitalar. Psicol Estudo. 2006; 11(2):323-30.

10. Duarte MLC, Noro A. Humanização: uma leitura a partir da compreensão dos profissionais da enfermagem. Rev Gaucha Enferm. 2010; 31(4):685-92.

11. Machado EP, Haddad JGV, Zoboli ELCP. A comunicação como tecnologia leve para humanizar a relação enfermeiro-usuário na Atenção Básica. Bioethikos. 2010; 4(4):447-52.

12. Sá MC. A fraternidade em questão: um olhar psicossociológico sobre o cuidado e a "humanização" das práticas de saúde. Interface Comunicação Saúde Educação. 2009;13(1):651-64.

13. Lanzieri PG, Claro LBL, Bragança FCR, Montezano VRS, Silva CS. "Boa noite, bom dia HUAP!", uma experiência de humanização na formação de profissionais na área da saúde. Interface (Botucatu). 2011; 15(36):289-97.

14. Cruz J. Que médicos queremos? Uma abordagem a partir de Edmund D. Pellegrino. Coimbra: Almedina; 2012.

15. Masetti M. Ética da Alegria. São Paulo: Sinergias; 2011.

16. Minayo MC, Sanches O. Quantitivo-qualitativo: oposição ou complementaridade? Cad Saude Publ. 1993; 9(3):239-48.

17. Collet N, Rozendo CA. Humanização e trabalho na enfermagem. Rev Bras Enferm [online] [Internet]. 2003 [acesso 2013 Mar 22]; 56(2):189-92. Disponível em: http:// www.scielo.br/scielo.php?script=sci_pdf\&pid=S0034-71672003000200016\&lng =en\&nr $\mathrm{m}=\mathrm{iso} \& \operatorname{tng}=\mathrm{pt}$

18. Minayo MC. Dilemas do setor saúde diante de suas propostas humanistas. Cienc Saude Colet. 2004; 11(9):15-29. 
19. Morais GSN, Costa SFG, Fontes WD, Carneiro AD. Comunicação como instrumento básico no cuidar humanizado em enfermagem ao paciente hospitalizado. Acta Paul Enferm. 2009; 22(3):323-7.

20. Almeida I. Representações e expectativas dos profissionais dos serviços de pediatria do Hospital de Braga relativamente à intervenção dos "Doutores Palhaços" [dissertação]. Braga: Universidade do Minho; 2012.

21. Barros L. Psicologia pediátrica: perspetiva desenvolvimentista. 2a ed. Lisboa: Climepsi; 2003.

22. Gomes GC, Erdmann AL. O cuidado compartilhado entre a família e a enfermagem à criança no hospital: uma perspectiva para a sua humanização. Rev Gaucha Enferm. 2005; 26(1):20-30.

23. Troostwijk TD. The hospital clown: a cross boundary character. In: Litvack AD, editor. Making sense of: stress, humour and healing. Oxford: United Kingdom; 2006. p. 73-5.

24. Presidência da República Brasileira, Casa Civil. Estatuto da Criança e Adolescente. 13 de julho de 1990 [acesso 2013 Jan 6]. Disponível em: https://www.planalto.gov.br/ ccivil_03/leis/l8069.htm

25. Doca FNP, Junior ÁLC. Preparação psicológica para admissão hospitalar de crianças: uma breve revisão. Paidéia. 2007; 17(37):167-79.

26. Paula E, Foltran E. Brinquedoteca hospitalar: direito das crianças e adolescentes hospitalizados. Conexão [Internet]. 2006 [acesso 2010 Nov 15]; 3. Disponível em: http://www.uepg.br/revistaconexao/revista/edicao03/artigo4.pdf

27. Mazur A, Batista GL, Andreatta D, Ribas M, Campos T. O processo de hospitalização da criança sob a ótica do familiar. 25 [Internet]. 2005 [acesso 2011 Mar 25]. Disponível em: http://bvsms.saude.gov.br/bvs/publicacoes/57cbe/resumos/834.htm.

28. Redondeiro M. O quotidiano hospitalar da criança: constrangimentos e possibilidades de desenvolvimento [dissertação]. Braga: Universidade do Minho; 2003.

29. Masetti M. Soluções de palhaços: transformações na realidade hospitalar. São Paulo: Palas Athena; 1998.

30. Meisel V, Chellew K, Ponsell E, Ferreira A, Bordas L, García-Banda G. The effect of "hospital clowns" on distress and maladaptive behaviours of children who are undergoing minor surgery. Psicothema. 2009; 21(4):604-9.

31. Melnyk B, Alpert-Gillis L, Fischbeck N, Crean HF, Johnson J, Fairbanks E, et al. Creating opportunities for parent empowerment: program effects on the mental health/ coping outcomes of critically III young children and their mothers. Pediatrics. 2004; 113(6):597-697.

32. Trianes MV. O stress na infância. Lisboa: Edições Asa; 2004.

33. Junqueira MF. A mãe, seu filho hospitalizado e o brincar: um relato de experiência. Est Psicol. 2003; 8(1):193-7.

34. Schmitz SM, Piccoli M, Vieira CS. A criança hospitalizada, a cirurgia e o brinquedo terapêutico: uma reflexão para a enfermagem. Cienc Cuidado Saude. 2003 2(1):67-73.

35. Butler R, Green D. The child within: taking the young person's perspetive by applying personal construct psychology. 2a ed. London: John Wiley \& Sons; 2007.

36. Goldenstein E. Um estudo preliminar sobre humanização hospitalar: dando voz a médicos de UTI pediátrica. São Paulo: Pontífica Universidade Católica; 2006.

37. Oliveira LDB, Gabarra LM, Marcon C, Silva JLC, Macchiaverni J. A brinquedoteca hospitalar como factor de promoção no desenvolvimento infantil: relato de experiência. Rev Bras Crescimento Desenvolvimento Hum. 2009; 19(2):306-12. 
38. Barros L. As consequências psicológicas da hospitalização infantil: prevenção e controle. Anal Psicol. 1998; 15(1):11-28.

39. Darbyshire P. Parents, nurses and pediatric nursing: a critical review. J Adv Nurs. 1993; 18(11):1670-80.

40. Kumamoto LH, Barros RT, Carvalho RN, Gadelha EM, Costa R. Apoio à criança hospitalizada: proposta de intervenção lúdica. In: Anais do $2^{\circ}$ Congresso Brasileiro de Extensão Universitária de Belo Horizonte; 12 a 15 de setembro; 2004 [acesso 2013 Jan 6]. Disponível em: https://www.ufmg.br/congrext/Saude/Saude23.pdf

41. Tavares P. "Acolher brincando". A brincadeira terapêutica no acolhimento de enfermagem à criança hospitalizada [dissertação]. Porto: Universidade do Porto; 2008.

42. Kiche MT, Almeida F. Brinquedo terapêutico: estratégia de alívio da dor e tensão durante o curativo cirúrgico em crianças. Acta Paul Enferm. 2009; 22(2):125-30.

43. Oliveira AS, Luengo FC, Barros FO. Brinquedoteca: proporcionando reflexões sobre três exemplos significativos. s/ d [acesso 2013 Mar 22]. Travessias [Internet]. Disponível em: http://www.google.pt/url?sa $=$ t\&rct $=j \& q=\& e s r c=s \&$ source $=$ web \&cd $=1 \& v e d=0 C D$ AQFjAA\&url =http \% 3A\% 2F\% 2Fe-revista.unioeste.br\% 2Findex.php \% 2Ftravessias\% 2Fart icle\% 2Fdownload\% 2F3273\% 2F2586\&ei=jrFeUe_1K7KP7AbzjICACg\&usg=AFQjCNHTw-CNUYNQHMH6iGFoP2lz2Mo6A.

44. Favero L, Dyniewicz AM, Spiller A, Fernandes L. A promoção do brincar no contexto da hospitalização infantil como ação de enfermagem: relato de experiência. Cogitare Enferm. 2007; 12(4):519-24.

45. Oliveira R, Oliveira I. Os Doutores da Alegria na unidade de internação pediátrica: experiências da equipe de enfermagem. Rev Enfermagem. 2008; 12(2):230-6.

46. Melo A. A terapêutica artística promovendo saúde na instituição hospitalar. Ibérica: Revista Interdisciplinar de Estudos Ibéricos e Ibero-Americanos. 2007; 1(3):159-89.

47. Mitre R, Gomes R. A promoção do brincar no contexto da hospitalização infantil como ação de saúde. Cienc Saude Colet. 2004; 9(1):147-54.

48. Masetti M. Boas misturas. São Paulo: MMD Editores; 2003.

49. Hart R, Walton M. Magic as a therapeutic intervention to promote coping in hospitalized pediatric patients. Ped Nursing. 2010; 36(1):11-7.

50. Mussa C, Malerbi KF. O impacto da atividade lúdica sobre o bem-estar de crianças hospitalizadas. Psicol Teoria Pratica. 2008; 10(2):83-93.

51. Vagnoli L. Clown, musica, animali: attività di supporto nell'ospedale pediatrico. Giornale Italiano di scienze Infermieristiche pediatriche. 2010; 2(2):64-7.

52. Fernandes $S$, Arriaga P. The effects of clown intervention on worries and emotional responses in children undergoing surgery. J Health Psychol. 2010; 15(3):405-15.

53. Lima R, Azevedo E, Nascimento L, Rocha S. A arte do teatro clown no cuidado às crianças hospitalizadas. Rev Esc Enfermagem-USP. 2009; 43(1):186-93.

54. Wuo AE. O clown visitador no tratamento de crianças hospitalizadas [dissertação]. Campinas: Univeridade Estadual de Campinas; 1999.

55. Achcar A. Palhaços de Hospital: proposta metodológica de formação [tese]. Rio de Janeiro: Universidade Federal do Estado do Rio de Janeiro; 2007.

56. Valladares A, Carvalho A. A arterapia e o desenvolvimento do comportamento no contexto da hospitalização. Rev Esc Enfermagem-USP. 2006; 40(3):350-5.

57. Moreira R. Dissonâncias cognitivas: o impacto do Doutor Palhaço numa enfermaria pediátrica. Lisboa: Centro de Estudos da Operação Nariz Vermelho; 2005 [acesso 2011 Maio 21]. Disponível em: http://repositorio.ipl.pt/ 
58. Masetti M, Caires S, Brandão D. Health staff perceptions regarding the work of Doutores da Alegria's Hospital clowns. In: Third International Conference on Health, Wellness, and Society; 15-16 March 2013; Escola Paulista de Medicina - Universidade Federal de São Paulo, Brazil; 2013. (s/p)

59. Oswald W. Para uma humanização da saúde. In: Serviço de Humanização do Hospital de S. João. Livro branco da humanização. Porto: Hospital de S. João; 2008. p. 25-8.

60. Brito P. Humanização, o outro nome da qualidade. In: Serviço de Humanização do Hospital de S. João. Livro branco da humanização. Porto: Hospital de S. João; 2008. p. 31-4.

61. Organização Mundial de Saúde. Men, ageing and health: achieving health across the span. Geneve: OMS; 2001.

62. Branco ME. João dos Santos saúde mental e educação. Lisboa: Coisas de Ler; 2010.

63. Goleman D. Emoções destrutivas. Mafra: Círculo de Leitores; 2006.

Esteves $\mathrm{CH}$, Antunes $\mathrm{C}$, Caires S. Humanización en contexto pediátrico: el papel de los payasos en la mejora del ambiente vivido por el niño hospitalizado Interface (Botucatu). 2014; 18(51):697-708.

Valorizando la importancia de los aspectos psicosociales de la internación pediátrica y buscando al niño "por detrás" del cuerpo enfermo, varios hospitales han invertido en la humanización de sus espacios, rutinas y atmósfera, promovendo ambientes acogedores y atenuadores de las experiencias negativas vividas por el niño durante la internación. En el presente artículo, juntamente con un intento de sistematización de esfuerzos hasta la fecha en el ámbito de la definición de "humanización", principalmente en el contexto pediátrico, se reflexiona sobre las potencialidades de algunos programas existentes, principalmente aquellos que unen el arte, la recreación, el ocio y el humor como medios privilegiados de comunicación y de expresión. Entre ellos, los autores destacan la intervención de los payasos de hospital, como promotora de la libre expresión del niño, de su autonomía, creatividad, exploración y conocimiento del mundo y su desarrollo psicosocial.

Palabras clave: Pediatría. Humanización. Payasos de hospital.

Recebido em 19/06/13. Aprovado em 13/07/14. 